\title{
Midwifery practice arrangements which sustain caseloading Lead Maternity Carer midwives in New Zealand
}

\author{
Andrea Gilkison ${ }^{A, B}$ PhD, MEd (Dist), BA, RM - Judith McAra-Couper ${ }^{B}$ PhD, BA, RM - Jackie Gunn \\ MA (Hons), BHSC (Ng), Adv Dip Ng, Cert Adult Tchg, RM, RGON - Susan Crowther PhD, MSc, BSC, \\ (Hons), RM, RN • Marion Hunter ${ }^{B}$ MA (Hons), BA, RM • Debbie Macgregor ${ }^{B}$ MHPrac (Midwifery), RM \\ - Claire Hotchin ${ }^{B}$ MA (Hons), BSN, IBCLC, RM, RGON
}

${ }^{\mathrm{A}}$ Corresponding Author: andrea. gilkison@aut.nz

${ }^{B}$ School of Midwifery, AUT University, New Zealand

\begin{abstract}
:
Background: The New Zealand Lead Maternity Carer (LMC) midwifery model has benefits for women and babies and is a satisfying way to work for midwives. Due to the need to be on-call for long periods of time, there have been questions raised about the sustainability of the model for midwives and the potential for burnout.

Objective: This qualitative descriptive study explored what sustains on-call, caseloading Lead Maternity Carer (LMC) midwives in New Zealand.

Methods: Eleven midwives with 12 to 20 years in practice were interviewed and thematic analysis used to identify themes which sustained these LMC midwives in practice.

Findings: Overall, the study found that it was the joy of midwifery practice, managing the unpredictability of being on-call, having clear boundaries, having good relationships with colleagues, having supportive families and friends, and workable practice arrangements which sustain them in practice. This paper presents the findings from the theme: workable practice arrangements. The midwives interviewed explained that having regular time off, a manageable caseload size, working together as a practice, the financial arrangements, and the sharing of arrangements with women created a sustainable way to practice.
\end{abstract}

Conclusion: This paper has identified aspects of sustainable practice which are congruent with the international research but also very specific to the New Zealand model of midwifery.

Key words: Caseloading, midwives, practice arrangements, sustainability

\section{INTRODUCTION AND BACKGROUND}

Implementing caseload, continuity of care, midwifery models improves outcomes and has significant benefits for the woman and baby (National Health Service, 2014; Sandall, Devane, Soltani, Hatem, \& Gates, 2010; Sandall, Soltani, Gates, Shennan, \& Devane, 2013), and enhances women's and midwives' satisfaction (Collins, Fereday, Pincombe, Oster, \& Turnbull, 2010; Ministry of Health, 2011).

The New Zealand Nurses Amendment Act (1990) provided New Zealand midwives with the legal ability to practise as autonomous health professionals. Midwives in New Zealand are funded by the government to provide midwifery care throughout pregnancy, labour, birth and the postpartum period up to six weeks, for women who have chosen to book with them (Ministry of Health, 2007). To support this continuity of care for women, New Zealand midwives are able to work as a Lead Maternity Carer (LMC) and provide care to a caseload of women. The predominant choice as LMC is a midwife (Ministry of Health, 2012), however, a general practitioner or an obstetrician can fulfil this role; it is the woman who determines who her LMC will be.

Providing LMC care to a caseload of women often means that the midwife needs to be available to her caseload at any time of the day or night - to provide care during labour or for any urgent or emergency issues (Ministry of Health, 2007). For some midwives this requirement is unsustainable and it has been argued may potentially increase burnout (Young, 2011), whilst for others it is enjoyable and satisfying (McAra-Couper et al., 2014). Our wider study aimed to explore what it is about working as a LMC midwife, providing continuity of care, which sustains midwives and supports them to continue to work in this role. A previous paper has described this study and the main themes summing up what sustained them in practice were identified as: the joy of working in partnership with women; having good collegial relationships with practice partners who are philosophically aligned; managing the unpredictability of being on-call; having clear boundaries; having good relationships with colleagues in maternity units; having supportive families and friends; and the way the practice was organised (McAra-Couper et al., 2014).

This paper reviews the specifics of practice arrangements which contributed to sustainable midwifery practice for our participants. In $2013,38.1 \%$ (1,118 midwives) of the New Zealand midwifery workforce reported caseloading as their main work situation, $86 \%$ of the caseloading midwives worked as self-employed LMCs (Midwifery Council of New Zealand, 2013). Midwives who work 
as LMCs do so in various ways from working on their own, in pairs working together, to small group or larger group practices. Government funding enables free maternity care to New Zealand resident women regardless of where they choose to birth (Ministry of Health, 2007). LMC midwives are legally able to access named maternity facilities within their local community. Midwives choose their work situation, which may be to work as a LMC, or as a core midwife, i.e., employed to staff hospitals and maternity units. The continuity of midwifery care approach made possible by the New Zealand LMC midwifery model is viewed by the international midwifery community as providing an outstanding service (Grigg \& Tracy, 2013). It is important that New Zealand is able to present research demonstrating what helps sustain this intensive on-call, LMC (practice) mode of working so that this may inform present and future maternity service provision both locally and internationally.

\section{Caseloading makes a difference}

A 2013 Cochrane review found that women who had midwife-led continuity of care were more likely to experience no intrapartum analgesia or anaesthesia, and a spontaneous vaginal birth, and less likely to experience regional analgesia, episiotomy and an instrumental birth. In their meta-analysis, Sandall et al. (2013) found a higher rate of maternal satisfaction amongst women who received midwifery-led continuity care. There was also a costsaving effect with midwife-led continuity of care compared to other care models (Sandall et al., 2013; Tracy et al., 2013).

Women in New Zealand have expressed satisfaction with the LMC model of care (Ministry of Health, 2011). For midwives, providing continuity of care to women is a satisfying way to work, and in itself contributes to sustainable practice (Collins et al., 2010; Edmondson \& Walker, 2014; Sandall et al., 2013). Sustainable is defined as something which is "able to be maintained". So in the context of this study, sustainable midwifery is a way of practising which will ensure that LMC midwifery can be maintained, whilst retaining the integrity of the mental, emotional and physical wellbeing of the midwife.

\section{The experience of caseloading midwives}

Whilst the benefits of caseloading midwifery for women and midwives are clear, recent New Zealand studies have focused on the challenges of providing caseloading and continuity of care. These difficulties relate to being on-call, work/life balance and burnout (Cox \& Smythe, 2011; Donald, Smythe, \& McAraCouper, 2014; Young, 2011). These studies offer important insights into the experiences of some caseloading midwives who have found caseload work challenging, yet clearly other midwives are able to sustain LMC practice for many years. There is little in the NZ midwifery literature to date regarding the specific practice arrangements which can help grow a sustainable caseloading midwifery practice.

This study aims to fill this gap by exploring specific practice arrangements which midwives themselves consider to be sustainable. Given the importance of continuity of care as a model of care which is of benefit to women, it is important to investigate what has sustained LMC midwives who have worked in the LMC model of midwifery care for more than eight years within the New Zealand context.

\section{METHOD}

The research design consisted of face-to-face interviews with 11 LMC midwives who had been in practice between 12-20 years. Participants were recruited by sending a letter and participant information sheets via email through the networks available to the researchers. Midwives self-selected as participants, and some passed the information onto other midwives who met the criteria for the study. Participants included both rural and urban midwives from the North Island of New Zealand. None of the participants worked together in the same practice at the time of the interviews. Before agreeing to participate in the study, potential participants were given an information sheet explaining the purpose of the study and were asked to complete a written consent form indicating their willingness to participate in the research project and to the taping of the interview. The interviews were conducted by a research assistant, or a member of the research team, at a time and place that was suitable for both the interviewer and interviewee. Participants were asked about what sustains them in midwifery practice. Each interview was transcribed and returned to participants, giving them an opportunity, should they wish, to change or remove any data. Minor corrections were requested by some participants, but no data were removed.

Each transcript was read by all the research team to obtain a good understanding of the data. Using a qualitative descriptive approach, informed by Sandelowski (2010), thematic and content analysis was used to group data into themes which emerged. Themes were identified and mutually agreed amongst the research team. Once the initial themes were identified they were revised until final themes and sub themes emerged showing what sustained LMC midwives in practice for longer than eight years.

The study conformed to the ethical principles of the AUT ethics committee (AUTEC), and ethical approval for the study was granted through AUTEC in 2011.

\section{FINDINGS}

This paper explores in detail the theme related to sustainable midwifery practice arrangements. The findings show that these five aspects help create a sustainable way to practice: having regular time off, having a manageable caseload size, the way midwives work together as a practice, the financial arrangements and the sharing of arrangements with women.

\section{How practices work}

The LMC midwives in this study all spoke of how they worked within their own practices. Regular practice meetings were one area which they saw as important. The purpose of the meetings varied, and ranged from having a social catch up, to discussing birth plans for women who were due, to serious debriefing and problem solving related to practice or clinical dilemmas. Some went as far as indicating that, for them, these meetings were the "glue" that held the practice together. In Debra's practice they meet weekly on Mondays:
You want similar things for your women. You couldn't get other midwives to cover you that didn't kind of work in a similar way. It could be quite disastrous, for the woman as well. And having a weekly meeting like - you know - checking in with each other, being able to talk over anything that's happened, that's bothering you. (Debra)

In Karen's practice they have a weekly lunch meeting, and also a longer meeting every two months to discuss practice issues in more depth.

At the moment, we have weekly lunch meetings. And then there's a more prolonged meeting every two months where we get together and talk about practice issues, things that would happen at access holders meetings, discuss our caseloads, and work out who was going to cover and be 2nd midwife for each other's clients. (Karen) 
It seems from the data that it is also important for sustaining practice that the day-to-day practice arrangements, a "check in" on how things are going, what is and is not working, are discussed and revisited on a regular basis:

We're always kind of revisiting how we work as a practice.
We have a meeting every fortnight. We used to have weekly
meetings but it just seemed to be too often. So we have a
practice meeting for an hour and a half every fortnight.
We just talk about the house that we rent and keep things
humming along there...'cause we love having a really nice
environment and keeping things updated. I have to say
I've been to a few midwifery practices where I think, 'oh,
gosh.' You know...'feels like a second hand shop here.' And
so I think having a nice environment is important and
respectful. (Psu)

Participants in this study agreed that regular practice meetings are essential to keep the midwives in touch with each other and to share things that have happened or to discuss things they are concerned about. The meetings also provide an opportunity to organise second midwife back-up or talk about wider practice issues, such as the clinic environment and shared purchases for the practice facilities. Sustainable LMC midwifery practice requires good support and communication amongst practice members. Regular meetings are key to facilitating this.

\section{Sharing arrangements with women}

The other arrangement which helps sustainability of practice is how the practice arrangements are shared with women. Taking time to explain and discuss the way the practice works appears very important. In Psu's practice, for example, a phone conversation happens first, during which the midwife explains how the practice works in terms of philosophy and midwife time off. Then, if the woman thinks such an approach will work for her, a half-hour appointment is made to further explain the philosophy and practice arrangements face to face. In this way when the woman comes to book in, she knows exactly what she can expect from her midwifery care, whichever midwife becomes her LMC, whichever midwife is the back-up. It provides the foundations for a wellfunctioning, sustainable partnership. This sharing of arrangements underpins the concept of partnership through dialogue that is clear about how the practice works.

We talk a lot over the phone initially just to let them know how we work. Then if she says, "oh, yeah that all sounds fine..." we'll make a half-hour appointment at the clinic where we offer information about the practice philosophy, how we work, the back-up midwife, the time off... (Psu)

One further question we asked midwives in this study was about antenatal care, and the timings and length of antenatal clinic visits.

\section{I normally allow an hour for each visit. I mean I guess if there is such a thing as a routine antenatal visit it might be sort of 40 minutes or 45 minutes but I think the business of the visit is three minutes actually, isn't it... in terms of what you do but the chat is so important isn't it? I really enjoy having the time to spend that long with the women. (Debra)}

There was a range of responses in relation to the time required for a booking visit, i.e., from 1 to $1 \frac{1}{2}$ hours, and return visits from half an hour and up to 1 hour. It seems for these midwives that a substantial length of time for antenatal care was important. Participants in this study noted their impression that when women's questions and needs were met during the antenatal visits, then the number of out of hours calls were reduced.
I just needed more down time. I didn't enjoy rushing with half-hour appointments and rushing women through wasn't that satisfying, you know, and I just wanted it to be more relaxed... and if you've done your homework really well antenatally, then they'll generally phone you less with minor questions and do better in the labour and birth. (Ali)

The strategy of making sufficient time to ensure that visits are unhurried for each woman and midwife resulted in less stress and promoted satisfaction. In addition, communicating practice arrangements well to women reduced the frequency of phone calls for minor questions at a later date. Arrangements which created rational boundaries around contact by women were central to sustaining LMC practice for the midwives in this study.

\section{Caseload size}

The LMC midwives in this study spoke about having a manageable caseload size as being one of the factors which sustained them. There remains a question as to what is a "manageable" caseload. The New Zealand College of Midwives recommends between 40-50 women a year (New Zealand College of Midwives, 2008). Our participants agreed that a range of 4-6 women a month for them is a sustainable case load, as this enabled them to give quality antenatal, intrapartum and postnatal care.

We probably all stayed between 4-6 women a month.
Sometimes you'd have a lot of births in one month, maybe
you'd end up with 8, but then the next month you'd have
a smaller month but 4-6 seems to be a really good model
when you're doing all your own postnatals and we like to
give plenty of time to women antenatally and postnatally.
(Karen)

Practice is sustainable when all practice partners have a similar caseload size, so that when a midwife is having her time off, the midwife who is covering is not overwhelmed with extra work. Participant Ali highlights that it is important to have a similar caseload to other midwives in the group..."so that we're not covering too much... Two of us work together... so that when one of us is off the other isn't swamped."

Caseload size is important not only for ensuring that midwives have enough time to feel satisfied and confident that they have provided quality care to their own clients but also when covering for their practice partners. For the midwives in this study, the size of their caseload is linked to the quality and safety of the care they give. Caseload, however, is also inextricably linked to the financial arrangements of self-employed LMC midwives because caseload size determines income.

\section{Time off}

Participants were asked whether they had regular time off and, if so, how those arrangements were made. Findings revealed two categories in relation to midwives having time off; there was the annual long holiday break on one hand and, on the other, regular time off-call, usually scheduled over a weekend. In the midwives' practice groups, time off tended to be negotiated and planned a year in advance so that when practice midwives had scheduled time off, this would be covered within the practice itself as opposed to needing to organise a locum midwife or reliever.

Some midwives negotiated one to two months off per year with their practice partners. One profession-specific aspect of managing a prolonged period of leave is midwives needing to take the precaution not to book women who were due one week either side of their time off. There are two reasons: so that practice partners would be less likely to be covering for too many women due to 
birth; and a woman then has the option of not booking with a midwife who is due to go on holiday the month in which the woman's baby is due. Participant Georgia says that to get a full month off, she needed to restrict bookings for a number of weeks prior to, and after her planned leave dates:

I usually have two months off a year.... well try to. I get one full month off, but by the time you are finishing up and women not being due when you come back.. you're basically looking at a two month timeframe, otherwise it's not satisfactory for the women... I haven't booked any women in December so I should be finished all my Novembers so I don't stress my partners by them having to run their caseloads and then pick up post-natals from me, as that kind of added onto your caseload at a critical time... I've got women due when I come back but not too close, most of them are due two weeks after I come back. (Georgia)

Midwives had different arrangements for having regular nights or weekends off. Some had a first-second on-call system for each weekend and, as Holly says, it is only once a month that she is on-call: "It's only about once a month (that I am on-call) we have a first on-call, second on-call person. It works out pretty well..." (Holly)

In Psu's practice, she goes off-call for 24 hours on a Thursday night, and then if it is her monthly scheduled weekend off, Psu has Thursday night through to Monday morning off-call and she feels as if she has a mini holiday:
I love it during the week that I might work really hard Monday to Thursday night but I know 5 pm Thursday night my phone goes off and I've got 24 hours. If it's my weekend on I've got 24 hours now to chill or go out for dinner or stay up late if I want to and then if it's my weekend off as well, I've got like a mini-holiday. I've got Thursday night to Monday morning... I do highly recommend that that's what people should do if they want to do this for more than a year or two. (Psu)

In Debra's practice, they employ a paging system so that each night one of the midwives in the practice takes all the overnight calls:

\begin{abstract}
The way that our practice manages that is that we have a paging system where all the midwives get all the messages on the pager. So at 6 o'clock every evening all the midwives turn off their pagers and just one of us takes all the calls over night and the same happens at the weekend so you're not constantly tied to your pager and nobody gets your cell phone number. So there's no texting, so you actually are available when you want to be available and if women are trying to contact you out of hours, if it's your night on call then yes, they'll get you. Otherwise they'll get somebody else who will say [for non-urgent calls], "look call after 9am in the morning." (Debra)
\end{abstract}

These midwives recognised that regular planned time off was essential if they were going to sustain themselves in LMC practice long term. Alongside manageable caseloads, securing arrangements for having time off was one of the most significant features of sustainable practice.

\section{Financial arrangements}

Midwives in this study spoke of a variety of financial arrangements, sometimes very detailed, and sometimes inexact but whatever the arrangements were, midwives said it was crucial that clear, agreed, financial arrangements were negotiated by the practice at the beginning, and were very clear to all midwives in the practice.
Financial arrangements were important, particularly when the LMC midwife was having time off, and the back-up midwife looked after a woman who birthed. LMCs in New Zealand are paid modular payments at the completion of each woman's antenatal trimesters, intrapartum care and at the six-week discharge postpartum. The largest proportion of the modular payment system is the labour and birth payment.

One example of a financial arrangement is a "swings and roundabouts" (give and take) arrangement which would work for midwives who had a similar caseload size.

We each put in our claims and the money is paid into one
account and we just divide it... I never even count up who
has done more births. I don't even want to go there...it just
puts complete trust in that it is "swings and roundabouts".
(Jane)

Psu said that because she has a smaller caseload than her back-up midwife, they can't just follow a "give and take" arrangement, so her practice has arranged a sliding scale around the birth fee:

If the back-up midwife looks after the woman, the midwife gets half the birth fee and then if she is with the woman for any longer than six hours she gets an extra $\$ 40$ or $\$ 50$ an hour. So that really kind of honours her work but it doesn't take the whole birth fee away from the LMC. (Psu)

Others spoke of paying a percentage of their income into a pool or reserve of money, referred to as a "kitty", to pay for rent, paging system and equipment, etc.

\begin{abstract}
Another part of our structure is that we all pay 5\% of our income into the kitty and that pays for our rent and paging system and all of the equipment and that kind of thing... We own a house together so we do have another layer of complexity in our practice. The practice is a company who are the house owning entity which meant that other people can come in and out of the practice without having to come in and out of owning the house because we could see that that might become problematic in the future. People do have the option of becoming shareholders in the house owning part of the business but generally people don't want to do that. (Debra)
\end{abstract}

\section{Alongside manageable caseloads, securing arrangements for having time off was one of the most significant features of sustainable practice.}

Midwives reach agreements about financial arrangements that suit their own practice group requirements, caseloads and individual circumstances. There is no "one size fits all" when it comes to financial arrangements and the practice partnerships within those groups. Whatever the arrangements, whether it is "swings and roundabouts" or "paying into a kitty" it needs to be mutually agreed, articulated and revised regularly in order that it works for each particular group. Financial arrangements will vary, but it appears important for sustainability that the financial arrangements are well understood, and mutually agreed to, by all within the practice. This supports the practice to function well and ensures optimal relationships within the practice. 


\section{Process for new LMC midwives joining a practice}

Debra spoke of what happens when new midwives were thinking of joining their practice. For her it appeared to be important to sustaining practice that new midwives know how the practice works, and time is spent considering whether the new practice partner is philosophically aligned and wants to work with the arrangements established in the practice. As Debra says:

\begin{abstract}
If somebody wants to join us we have them approach us by writing us a letter telling us about themselves and about their midwifery philosophy and why they were attracted to come and work with us. Then we invite them to come and have a meal or something and just get them to come and meet with us. Often we know them already because they may have been students that worked in our practice and we really love it when that's the process that happens because they're a bit of a known quantity for us as well. That gives us an opportunity to talk to them about what it is that they might need from us but also how it is that we function and what we might require of them, mostly particularly if it's a new graduate midwife. (Debra)
\end{abstract}

Having a carefully thought through process for including new midwives into the practice protects the practice philosophy and ensures that agreed arrangements are maintained.

\section{DISCUSSION}

This paper has examined findings emerging from the theme "practice arrangements". This theme reveals the constituents of practice agreements and their role in supporting sustainable LMC midwifery practice. Analysis of the theme "practising arrangements" has shown that when setting up sustainable caseloading midwifery practice, it is crucial that all midwives in the practice think through, negotiate, and reach agreement about: taking regular time off; aligning caseload size; how they will work together as a practice; committing to regular meetings; having clear financial arrangements; and sharing the practice arrangements with all women before they book with a LMC midwife from the practice. The arrangements need to be revisited and articulated on a regular basis to optimise their positive effect on sustainable LMC midwifery practice.

Practice arrangements by themselves do not sustain LMC midwives. They are an essential part of a complex whole which includes the other six themes identified in our research and discussed in a previous paper. In addition to "the way the practice is organised", these were: "the joy of working in partnership with women"; "having good collegial relationships with practice partners who are philosophically aligned"; "managing the unpredictability of being on call"; "having clear boundaries"; "having good relationships with colleagues in maternity units"; "and having supportive families and friends" (McAra-Couper et al., 2014).

Limiting caseload size when providing continuity of care to women has been identified as essential in other studies. Collins et al. (2010), in their research into the sustainability of a caseloading practice in Australia, found that having a manageable caseload was important as the volume of work had an impact on sustainability. This included the need to consider when midwives were on leave, the impact of travel times, the needs of the women and time spent in meetings. For the New Zealand midwives in this study, sustainability included limiting caseload size but also managing the caseload to ensure that practice partners were not expected to cover a routine normal workload because due dates were not considered or booked regardless during their leave periods.
In another Australian study, Edmondson and Walker (2014) found that an arrangement, where: midwives worked in a partnership of two midwives who covered for each other's holidays; took a relatively small caseload of 40 women per annum; and hours of work were determined by the midwives, created a more sustainable way to organise the practice. Caseload size was also seen as important for an Australian Midwifery Group Practice (MGP), where three full-time midwives took a personal caseload of 40 women per year each, and within each group practice provided back-up for each other through an on-call arrangement. (Toohill, Turkstra, Gamble, \& Scuffham, 2012). The New Zealand College of Midwives (2008) recommends a caseload of between 40-50 women a year and, in the United Kingdom, the "One to One" midwives take a caseload of 40 women per year (National Health Service, 2014). Our study aligns with these and endorses the potential of caseload size to impact on sustainability for the midwife. The New Zealand midwives we interviewed found that a caseload of between 4-6 women a month worked best. This essentially translates to between 40 and 50 women annually, when annual leave of four to eight weeks when no women are booked, is taken into account.

The main difference for New Zealand midwives, compared with those in Australia and the United Kingdom, is that they are selfemployed' so they make their own decisions regarding caseload size, days and times of work, time spent with women and decisions about who they work with. However, there is also a downside to being self-employed in that caseload size also has an impact on income. Our participants discussed a variety of ways of limiting loss of income if absent for a birth, and the need for clear financial arrangements within the practice.

\section{The main difference for New Zealand midwives, compared with those in Australia and the United Kingdom, is that they are self- employed so they make their own decisions regarding caseload size, days and times of work, time spent with women and decisions about who they work with.}

The findings of this study support those of Edmondson and Walker's (2014), who found that providing continuity of care, practising autonomously, having a good work-life balance, effective working relationships and clear guidelines for practice were important for caseloading midwives in an Australian birth centre. One of the key differences for the New Zealand midwives was the importance of being clear, and the sharing of their practice arrangements, with women. The New Zealand midwifery model of partnership is based on continuity of care, trust and informed decision making (Guilliland \& Pairman, 1995), and working in partnership extends to being explicit about practice arrangements with women.

This New Zealand study found that having effective working relationships, having a similar philosophy as practice partners, setting boundaries and having personal time off were central to the sustainability of practice (McAra-Couper et al., 2014).

Although this study cannot be generalised due to the small number of participants, the findings expand the knowledge and understanding about sustainable LMC midwifery practice 
Table 1: Guide to sustainable midwifery practice arrangements

Time off

Case load size

Financial

arrangements

\section{Sharing arangements} with women
As a practice, plan time off a year in advance where possible so that the holidays are staggered Plan to have 1-2 months off each year

Plan time off during the year with regular weekends and/or weeknights off call

4- 6 women per month for 10-11 months of the year as a full-time caseload is sustainable Caseload needs to be similar size to that of practice partner/s Important that financial arrangements are discussed, agreed and clear to all from the beginning Financial arrangements for back-up midwife who covers for the midwife on leave need to be agreed in advance.

May be a "give and take" arrangement

May have a specific percentage of birth fee going to the back-up midwife

Consider how rent, equipment, supplies are paid for

Describe the arrangements before women register (book in)

Include information about time off and back up arrangements, who to call, when and how arrangements for midwives working with a caseload of women in New Zealand. The findings provide an understanding of the principles of ensuring sustainable practice arrangements and can be used to provide guidance for midwives who are setting up, or joining a midwifery practice, and for midwifery service managers who are establishing caseloading LMC midwifery practices.

Table 1 summarises the findings from this study and could act as a guide to the essential elements and principles of sustainable midwifery practice arrangements.

\section{CONCLUSION}

This paper identifies the fundamental practice arrangements our participants found were needed to sustain self-employed caseload midwifery practice within the New Zealand model of maternity care. Each practice of midwives finds and defines its own unique arrangements for working together. The strengths of this study are that an in-depth analysis of 11 midwives' experiences of what sustains them in practice has identified aspects of sustainable practice which are congruent with the international research but also very specific to the New Zealand model of midwifery. A wider study of how LMC midwives arrange their practices would be useful to further enhance understanding of the sustainability of midwifery practice. The findings of this research provides guidance for midwives both in New Zealand and globally who seek guidance about how caseload midwifery can be organised sustainably.

\section{REFERENCES}

Collins, C. T., Fereday, J., Pincombe, J., Oster, C., \& Turnbull, D. (2010). An evaluation of the satisfaction of midwives' working in midwifery group practice. Midwifery, 26(4), 435-441. doi: 10.1016/j. midw.2008.09.004

Cox, P., \& Smythe, L. (2011). Experiences of midwives' leaving Lead Maternity Care (LMC) practice. New Zealand College of Midwives Journal, 44, 17-21.

Donald, H., Smythe, L., \& McAra-Couper, J. (2014). Creating a better work-life balance. New Zealand College of Midwives Journal, 49, 5-10.

Edmondson, M. C., \& Walker, S. B. (2014). Working in caseload midwifery care: The experience of midwives working in a birth centre in North Queensland. Women \& Birth, 27(1), 31-36. doi: 10.1016/j. wombi.2013.09.003

Grigg, C. P., \& Tracy, S. K. (2013). New Zealand's unique maternity system. Women and Birth, 26(1), e59-e64. doi: http://dx.doi. org/10.1016/j.wombi.2012.09.006

Guilliland, K., \& Pairman, S. (1995). The midwifery partnership: a model for practice. Wellington: Victoria University Press.
McAra-Couper, J., Gilkison, A., Crowther, S., Hunter, M., Hotchin, C., \& Gunn, J. (2014). Partnership and reciprocity with women sustain Lead Maternity Carer midwives in practice. New Zealand College of Midwives Journal, 49, 29-33.

Midwifery Council of New Zealand. (2013). 2013 Midwifery workforce survey. Wellington: Midwifery Council of New Zealand.

Ministry of Health. (2007). Primary maternity services notice 2007 NZ Government. Retrieved from http://www.moh.govt.nz/moh. nsf/pagesmh/5845/\$File/s88-primary-maternity-services-noticegazetted-2007.doc.

Ministry of Health. (2011). Maternity consumer survey. Wellington, New Zealand: Ministry of Health.

Ministry of Health. (2012). Report on Maternity. Wellington: NZ Government.

National Health Service. (2014). One to one quality account April 2013-March 2014. U.K: National Health Service.

New Zealand College Of Midwives. (2008). Midwives handbook for practice (3rd ed.). Christchurch: New Zealand College of Midwives.

New Zealand Government. (1990). Nurses Amendment Act. Wellington, New Zealand.

Sandall, J., Devane, D., Soltani, H., Hatem, M., \& Gates, S. (2010). Improving quality and safety in maternity care: the contribution of midwife-led care. Journal of Midwifery \& Women's Health, 55(3), 255261. doi: 10.1016/j.jmwh.2010.02.002

Sandall, J., Soltani, H., Gates, S., Shennan, A., \& Devane, D. (2013). Midwife-led continuity models versus other models of care for childbearing women. Cochrane Database of Systematic Reviews. doi: 10.1002/14651858.CD004667.pub3

Sandelowski, M. (2010). What's in a name? Qualitative description revisited. Research in Nursing \& Health, 33(1), 77-84. doi: 10.1002/ nur.20362

Toohill, J., Turkstra, E., Gamble, J., \& Scuffham, P. A. (2012). A non-randomised trial investigating the cost-effectiveness of Midwifery Group Practice compared with standard maternity care arrangements in one Australian hospital. Midwifery, 28(6), e874-879. doi: 10.1016/j. midw.2011.10.012

Tracy, S. K., Hartz, D. L., Tracy, M. B., Allen, J., Forti, A., Hall, B. ... Kildea, S. (2013). Caseload midwifery care versus standard maternity care for women of any risk: M@NGO, a randomised controlled trial. The Lancet. doi: http://dx.doi.org/10.1016/S0140-6736(13)61406-3

Young, C. M. (2011). The experience of burnout in caseloading midwives. Doctoral thesis, AUT University, Auckland, New Zealand.

\section{Accepted for publication March 2015}

Gilkison, A., McAra-Couper, J., Gunn, J., Crowther, S., Hunter, M., Macgregor, D., Hotchin, C. (2015) Midwifery practice arrangements which sustain caseloading Lead Maternity Carer midwives in New Zealand. NZCOM Journal 51, 11-16. http://dx.doi.org/10.12784/nzcominl51.2015.2.11-16 